\title{
REVISITANDO AS FUNÇÕES DA IMATURIDADE: UMA REFLEXÃO SOBRE A RELEVÂNCIA DO CONCEITO NA EDUCAÇÃO INFANTIL' ${ }^{1}$
}

\author{
Eulina da Rocha Lordelo \\ Ilka Dias Bichara
}

Resumo: $O$ entendimento sobre a natureza da infância pode ser crítico para várias áreas de investigação e aplicação. As últimas décadas assistiram ao trabalho de desconstrução do conceito de infância, baseando-se nas investigações de historiadores, antropólogos e psicólogos, que mostraram a intensa variabilidade social e cultural no modo como as sociedades e as épocas pensam sobre a infância e decidem como tratá-la. Ao mesmo tempo, ganha força o consenso social sobre a importância da educação desde os primeiros anos de vida, e sobre a escola como lugar privilegiado para a criança, afastada do mundo dos adultos, particularmente do mundo do trabalho. Essas idéias são orientadas de um lado por motivos pragmáticos - a necessidade de preparação da criança para inserção futura no mundo do trabalho, em condições competitivas - e de outro por motivos teóricos - a adoção de uma perspectiva sociocultural e contextualista extremada, que vê o ser humano em desenvolvimento como material plástico, sujeito tão somente aos condicionantes ambientais imediatos e históricos. Este artigo busca esclarecer as limitações de tais posições e propor,em seu lugar, uma agenda de pesquisa sobre a infância enquanto fenômeno biopsicossocial. Para tal, examina as idéias da psicologia evolucionista sobre a imaturidade da espécie humana, e os estudos mais recentes orientados por essa perspectiva, cobrindo tópicos como cognição e metacognição, aprendizagem, autoestima e brincadeira, entre outros. Finalmente, o artigo discute os problemas da organização da educação infantil no Brasil, seus currículos explícito e implícito e a congruência dessa organização com uma concepção biopsicossocial de infância.

Palavras-chave: Infância. Educação. Brincadeiras. Funções da imaturidade.

1 Essa pesquisa foi desenvolvida com apoio do Conselho Nacional de Desenvolvimento Científico e Tecnológico (CNPq). 
Este trabalho tem como objetivo o reexame da imaturidade da espécie humana, à luz da literatura informada pela teoria evolucionista aplicada à psicologia humana, particularmente à psicologia do desenvolvimento. Nós começamos pela caracterização da infância humana, discutindo o caráter da imaturidade como uma adaptação selecionada naturalmente, resumindo as evidências para tais alegações. Um foco especial será dado à brincadeira humana, como característica distintiva da infância, com prováveis impactos para a vida adulta, contextualizada no contexto da educação infantil. Em seguida, nós discutimos as implicações dessas visões para o modo como pensamos a infância, particularmente na organização da Educação Infantil.

\section{A espécie humana é neotênica}

Neotenia significa desaceleração do crescimento e retenção de características embriológicas ou juvenis na idade adulta (Bjorklund, 1997; Gould, 1977; Maynard-Smith, 1966; Moore, 2008). De onde vêm as evidências para essa afirmação?

Primatas vivem mais e amadurecem mais lentamente do que outros mamíferos de tamanho de corpo comparável e, entre os primatas, é a espécie humana que possui o desenvolvimento mais lento. Nós atingimos a puberdade quando temos cerca de $60 \%$ do peso adulto, os chimpanzés com pouco menos de $60 \%$ e a maioria dos animais de laboratório e de criação com cerca de $30 \%$ do peso adulto (Gould, 1977).

O retardo no desenvolvimento em humanos começa cedo e aumenta continuamente durante a embriogênese. Gould (1977) cita um estudo de Otis e Brent, de 1954, demonstrando que 147 marcos desenvolvimentais estudados em humanos e ratos seguem a mesma ordem de aparecimento, mas os estágios iniciais levam duas a quatro vezes mais tempo para se desenvolver em humanos. O padrão de retardamento ontogenético conforme as espécies é regular: grandes símios são geralmente maiores, amadurecem mais lentamente e vivem mais do que macacos e prossímios, sendo o retardo em humanos ainda mais pronunciado do que em outros primatas.

O retardo geral em ontogenia tem uma única exceção no caso humano, a gravidez, que vai a termo muito mais cedo do que o esperado. Gould (1977) cita antigo trabalho de Portmann (1945), que sugere que a espécie humana não foge tanto ao padrão, afinal; nós seguimos a tendência geral dos mamíferos quanto ao retardamento do desenvolvimento dos filhotes, bastando para isso considerar o primeiro ano de vida humana, aproximadamente, como desenvolvimento fetal extra-uterino. Explicações para o parto precoce tomam como base, de um lado, o conflito entre tamanho do cérebro e o andar ereto, que obrigou a espécie a antecipar o nascimento 
e, de outro, as características do desenvolvimento cerebral humano, que requer insumos ambientais para seu completo crescimento.

O peso do cérebro da maioria dos primatas já está quase completo ao nascimento. Entre os grandes primatas, entretanto, o crescimento do cérebro continua após o nascimento. Chimpanzés têm $40 \%$ da capacidade cranial ao nascimento, enquanto os humanos têm apenas $23 \%$ (Gould, 1977).

A neotenia humana parece ter sido uma tendência consistente em nossos ancestrais, aumentando regularmente nas linhagens que nos precederam. Baseados em evidências fósseis, Leakey e Lewin (1992) sugerem que o tamanho da infância aumenta regularmente na linha evolutiva de Australopithecus, Homo erectus e Homo sapiens.

A neotenia humana é uma adaptação? Antes de prosseguir, é importante ressaltar o sentido da palavra adaptação. Em sentido biológico, a principal evidência de uma adaptação é a existência de design especial. Segundo Tooby e Cosmides (1995), para se qualificar como adaptação, uma característica biológica deve ser um sistema de atributos que se desenvolvem confiavelmente, ocorrendo entre todos os membros de uma espécie. Uma adaptação torna-se incorporada ao design padrão de uma espécie quando, durante o período de tempo em que essa incorporação ocorreu, os traços em questão foram coordenados com características recorrentes do ambiente de evolução (ou de outras partes do organismo). Essa articulação entre traço e características do ambiente deve ter produzido resultados funcionais capazes de afetar a frequência dos genes em questão nas gerações seguintes, sobrepujando os designs alternativos. Seguindo os critérios propostos por Hamilton, em 1966, Tooby e Cosmides (1995) reconhecem como parâmetros para reconhecer "design especial": economia, eficiência, complexidade, precisão, especialização e confiabilidade.

Então, é importante distinguir os sentidos da palavra adaptação quando se fala de qualquer fenômeno psicológico. Em última análise, a diferença remete ao nível de análise em questão, se causal, funcional, ontogenética ou filogenética. Em linguagem comum e mesmo na teoria piagetiana do desenvolvimento cognitivo, adaptação descreve uma mudança no organismo, com vistas a enfrentar uma discrepância, dificuldade ou situação nova - no caso da teoria de Piaget, restaurando a homeostase do sistema vivo (Lutz \& Sternberg, 1999) e, portanto, no nível causal, próximo. Também no uso cotidiano que fazemos da palavra adaptação, descrevemos mudanças no presente, visando encontrar soluções para um problema. Nesse sentido, adaptação envolve flexibilidade comportamental para produzir um resultado no presente.

No sentido biológico, uma adaptação, especialmente uma adaptação complexa, é confiavelmente encontrada em todos os indivíduos da espécie, independentemente de seu funcionamento atual levar a bons ou maus resultados. Enquanto o comportamento é amplamente variável, uma adaptação biológica geralmente não o é. Assim, quando se pergunta se a 
neotenia humana é uma adaptação, busca-se saber se ela é encontrada em virtualmente todos os indivíduos da espécie; além disso, pergunta-se também se sua emergência foi uma resposta a certas características do seu ambiente de evolução, e que tornou seus possuidores mais bem-sucedidos em sobreviver e reproduzir-se, transmitindo essas características às suas proles. O fato de uma característica resultar em bons ou maus resultados no presente não necessariamente é relevante para qualificá-la como uma adaptação.

Também segundo Kurzban e Haselton (2006), a principal evidência de uma adaptação em psicologia evolucionária é exatamente a mesma aceita em biologia evolucionária: design especial. Existirão evidências de que a longa infância humana foi selecionada naturalmente contra alternativas prévias, pelo seu efeito em aumentar a aptidão dos detentores dessa característica?

Em primeiro lugar, do ponto de vista filogenético,é possível rastrear a tendência à neotenia no desenvolvimento dos primatas, em conexão com o aumento do tamanho do cérebro. A característica humana da neotenia é compartilhada com nossos parentes mais próximos e se acentuou no tempo. Assim, a neotenia humana tem sido relacionada ao tipo de história de vida que caracteriza a espécie. Somos estrategistas K (Pianka, 1970) - corpos grandes, maturação retardada, vidas longas, nascimentos únicos, poucos filhos no total e alto grau de socialização (Gould, 1977), tal como nossos parentes e ancestrais - quanto mais próximos estão da nossa espécie, mais estrategistas K eles parecem.

Segundo, o modo como o cérebro humano se desenvolve constitui evidência sugestiva do caráter de adaptação da neotenia humana. A criança humana é imatura porque o desenvolvimento do seu cérebro requer a exposição a certos estímulos e experiências diretas. Segundo Johnson (1999), o desenvolvimento do cérebro é fortemente dependente da atividade do organismo. A ideia corrente sobre plasticidade do cérebro deve ser algo corrigida: plasticidade não deve ser vista como o resultado de um mecanismo operando quando o desenvolvimento normal é perturbado. Em vez disso, plasticidade deve ser concebida como uma propriedade inerente do desenvolvimento, que se caracteriza como um processo de especialização, de "restrição do destino", ou seja, tecido e células tornam-se mais especializados durante seu desenvolvimento.

Assim, plasticidade pode ser entendida como o estado anterior à especialização. Se um tecido é danificado por qualquer razão, um vizinho pode assumir seu lugar, o que significa que muitos padrões anômalos de desenvolvimento cerebral podem ser vistos como resultados de processos normais de desenvolvimento. A plasticidade do cérebro, entretanto, não é genérica. Para alguns domínios, como a linguagem, por exemplo, há considerável plasticidade nos primeiros meses de vida, enquanto outros, como alguns aspectos da cognição espacial, parecem ser menos plásticos. 
Reconhecendo, então, a neotenia humana como design especial, e a brincadeira como sua característica fundamental, quais teriam sido os problemas que essa adaptação teria resolvido, no nosso passado ancestral, que conferiram aos seus detentores vantagens seletivas? Como a neotenia funcionaria no ambiente de adaptação evolutiva? Como a brincadeira, um tipo de atividade que se define pela ausência de propósito prático, poderia melhorar o funcionamento do indivíduo que a pratica?

\section{As funções da imaturidade}

Bjorklund (1997) discute a visão tradicional sobre a infância, que tende a tratar os estágios imaturos da vida apenas como passos necessários à forma adulta. Ele argumenta pela necessária atenção aos estágios imaturos da vida como importantes em si mesmos, como exemplificado pela lagarta e a borboleta. Embora essa última seja um resultado inevitável da primeira, seria insensato deixar de pensar na forma da lagarta como detentora de adaptações para o modo de vida específico para o qual foi selecionada. Afinal, lagartas precisam sobreviver. Olhar o organismo em cada estágio da sua vida como um ser com habilidades e recursos adequados às demandas do seu ambiente gera uma nova visão sobre o fenômeno da imaturidade.

Dessa perspectiva, segundo Bjorklund (1997), a imaturidade não é um mal necessário; em vez disso, é provável que a imaturidade desempenhe um papel adaptativo na vida e no desenvolvimento da criança.

A partir desses pressupostos, duas linhas de hipóteses e investigações têm se destacado: a primeira e mais tradicional delas vê a imaturidade como uma necessidade da espécie para aprender as complexidades da vida social do modo de vida típico caçador-coletor. Bruner (1976) argumentou fortemente pela importância da imaturidade na constituição da espécie, utilizando dados de observação sobre o período juvenil de grandes primatas e crianças humanas de povos caçadores-coletores.

Bruner assinalou a virtual ausência, entre esses grupos, do ensino estruturado de habilidades e conhecimentos, à semelhança da escola, e a frouxa transição entre trabalho e brincadeira ou lazer. As crianças convivem com os adultos e outras crianças todo o tempo. No desempenho cotidiano de suas tarefas, aprendem a fazer instrumentos de caça, como arcos e flechas, a preparar alimentos e a cuidar das crianças. Meninos caçam pequenos animais, como lagartixas e insetos diversos, e as meninas cuidam de outras mais jovens.

A análise de Bruner atribui a imaturidade e a longa infância da espécie à necessidade de preparação para a vida adulta. A complexidade da vida social humana e sua dependência de tecnologias ajustadas a um ambiente local são costumeiramente utilizadas para dar sentido à longa infância humana e seu forte envolvimento com atividades de brincadeira. 
Uma segunda linha de raciocínio, especificamente sobre a brincadeira infantil, trata a brincadeira como adaptação ontogenética. Nesse caso, não está em questão a função da própria imaturidade, mas o papel que o brincar pode desempenhar no desenvolvimento do indivíduo.

Uma adaptação ontogenética consiste num atributo anatômico, mental ou comportamental qualquer, cuja utilidade é limitada a um estágio específico do desenvolvimento. Ao nascimento, o bebê dispõe de vários reflexos importantes, sendo o principal o reflexo de sucção. Sem ele, o bebê provavelmente não sobreviveria, dada a sua incapacidade de coordenar os movimentos necessários para extrair o leite do seio materno. Mais tarde, o reflexo de sucção desaparece e sua função agora será desempenhada por outro conjunto de músculos. Então, o reflexo de sucção é obviamente uma adaptação ontogenética, um sistema indispensável nos primeiros meses de vida e sem maior utilidade mais tarde. Seguindo esse raciocínio, é possível que outros padrões comportamentais importantes na infância não tenham maior significado para a vida adulta, e não sirvam de preparação para ela. Pode ser o caso da brincadeira infantil, útil na infância, independentemente de seu efeito no futuro?

Uma das mais importantes contribuições nessa área se deu com a constatação de Byers (1998). Ele assinalou que, em quase todas as espécies estudadas, o gráfico de disposição para brincadeiras assume a forma de um $\mathrm{U}$ invertido, aumentando durante o período juvenil e daí caindo por volta da puberdade, período depois do qual a maioria não brinca muito, o que coincidia com o gráfico relativo ao desenvolvimento do cerebelo.

$O$ ato de brincar, então, poderia estar relacionado ao crescimento do cerebelo, desde que os dois atingem o seu pico mais ou menos ao mesmo tempo. Acredita-se que há um período sensível no crescimento do cérebro, uma janela de tempo durante a qual é necessário que o animal seja estimulado através de certas atividades, como brincadeiras, por exemplo, para esse crescimento. Parece evidente que o cerebelo precisa dos movimentos de todo o corpo na hora da brincadeira para obter sua configuração final. Ou seja, brincar ativamente pode ser mais importante para o desenvolvimento cognitivo do que ficar sentado, envolvido em alguma atividade de alta concentração como em jogos de tabuleiro, computador, ou mesmo em uma sala de aula.

Se entendermos a brincadeira como adaptação ontogenética, deveríamos ser capazes de demonstrar que ela melhora o funcionamento do indivíduo durante a infância. Que evidências existem para essa alegação? Algumas sugestões têm sido apresentadas, sem que haja ainda um corpo de conhecimento consistente que exclua outras explicações.

Por exemplo, Pellegrini e Smith (1998) aventaram algumas possibilidades. Eles sugeriram que o exercício da brincadeira proporciona à criança senso de domínio, competência e autoeficácia, através do desempenho bem-sucedido em tarefas com poucas exigências em eficácia e eficiência. 
Esses sentimentos de domínio, embora possam ser pouco significativos para o contexto onde decorrem, podem ter um impacto significativo no desempenho de novas atividades.

Essa visão é compatível com a teoria do desamparo aprendido (Seligman, 1977), que enfatiza a aquisição de matrizes cognitivas baseadas em experiências prévias de aprendizagem. $O$ contato com experiências em que a ação do indivíduo não tem efeito sobre as consequências do comportamento gera uma série de efeitos negativos para as aprendizagens futuras, levando o indivíduo, em casos extremos, à completa passividade.

Sentimentos de eficácia e eficiência, então, devem ser afetados pelas experiências na infância. Essa visão liga a brincadeira na infância à idade adulta indiretamente, de modo que o conteúdo da brincadeira em si mesmo pode ser inútil para a vida adulta. Brincar de casinha, nessa visão, não prepararia a menina para as funções de mãe ou dona-de-casa. Mas pode ter um efeito em metacognições - cognições sobre sua própria competência. Essas experiências seriam estruturadas em sistemas cognitivos complexos, com a necessária participação de emoções.

Uma possível ilustração do funcionamento desses mecanismos pode ser visto no uso de técnicas psicoterápicas que utilizam o brinquedo como principal procedimento de trabalho. A maior parte do trabalho terapêutico com crianças é feito por meio de brinquedos e brincadeiras, que são usados não apenas como meio de comunicação entre adulto e criança, mas também desempenham o papel de veículo de expressão de sentimentos e cognições. O caráter fortemente repetitivo das ações em ludoterapia é congruente com a ideia de que o exercício continuado de comportamentos resulta em efeitos positivos para a criança.

Tem sido difícil encontrar provas diretas de que a imaturidade e, no caso humano, a brincadeira que a caracteriza, são adaptações ontogenéticas que proporcionam vantagens atuais para a criança. Mas muitas possibilidades, que requerem mais investigação, têm sido aventadas. É o caso da hipótese formulada por Spinka, Newberry e Bekoff (2001) sobre a brincadeira na infância. Eles sugeriram que a brincadeira, especialmente a motora, ajuda o indivíduo jovem a enfrentar situações inesperadas, dandoIhe mais flexibilidade e versatilidade para lidar com situações inesperadas, necessidade de movimentos súbitos para evitar quedas e corrigir posturas em situações de perda de equilíbrio.

A imaturidade é um desperdício de energia? Pellegrini e Smith (1998), avaliando o dispêndio de energia consumida em brincadeiras, acreditam que o custo energético desses comportamentos tem sido superestimado, o que fortaleceria a hipótese da brincadeira como uma adaptação ontogenética. Um estudo de Pellegrini, Hovart e Huberti (1998) concluiu que, entre crianças de classe média, o consumo de energia em brincadeira não excede $6 \%$ de seus gastos energéticos totais. 
A alta motivação para a brincadeira infantil aponta para seu caráter de adaptação, como evidenciado indiretamente por estudos que submeteram crianças à privação dessa classe de atividade. Pellegrini e Smith (1998) relatam que, em tais casos, observa-se regularmente um recrudescimento da atividade de brincadeira em situações onde ela foi artificialmente impedida. Após a privação, o nível de atividade da criança aumenta sensivelmente, a um nível superior ao da linha de base.

Esse tipo de efeito é congruente com o aumento do nível de atenção que ocorre em atividades acadêmicas em situação escolar após o recreio (Pellegrini \& Smith, 1998). Esse resultado deve dirigir a atenção dos psicólogos e educadores para suas possíveis consequências em contextos escolares.

Bjorklund e Green (1992) têm sido os principais pesquisadores voltados para a questão da imaturidade humana, buscando revelar suas possíveis funções. Embora eles admitam que muitas das características da infância são adaptações para a vida adulta, eles têm analisado cuidadosamente as características da infância e identificado algumas possíveis vantagens advindas da imaturidade. Seus estudos permanecem um tanto especulativos, na medida em que é difícil demonstrar que uma estratégia neotênica é superior a uma mais acelerada. No entanto, suas investigações abrem caminho para um programa de pesquisa de mais longo prazo, capaz de fornecer essas evidências, se elas existirem.

Bjorklund \& Green (1992) propuseram, como hipóteses, que a imaturidade motora pode funcionar como uma proteção para a criança, impedindoa de afastar-se de sua mãe e expor-se a perigos do ambiente; analogamente, limitações sensoriais dos jovens poderiam ajudar a reduzir a quantidade de informações com as quais o organismo jovem tem de lidar, ajudando a criança a ter uma visão mais simplificada e compreensível do mundo.

Estudos diretos de possíveis vantagens da imaturidade são mais encontrados em funções cognitivas (Bjorklund \& Green, 1992). Esses autores mapearam algumas áreas de possíveis vantagens advindas da imaturidade da criança, como a aquisição da linguagem, egocentrismo, metacognição e velocidade de processamento da informação.

Os dados mais convincentes para a hipótese de que a imaturidade é uma adaptação vêm dos conhecimentos sobre aquisição da língua-mãe e de línguas subsequentes. Crianças aprendem a primeira e a segunda língua em alta velocidade, sem qualquer instrução direta. Quanto mais cedo essa segunda língua é aprendida, melhor é o resultado, em termos de desempenho e de velocidade. Esses bem conhecidos fatos sobre aquisição de línguas estão em completa congruência com o modo como o cérebro se desenvolve. Quanto mais aumentam certas habilidades, mais difícil é a aprendizagem de uma nova língua. $O$ desenvolvimento do cérebro humano é altamente dependente da atividade do organismo, utilizando-a como insumo para sua completa estruturação (Johnson, 1999). Uma vez que esse desenvolvimento avança, restringe-se o espectro de possibilidades. 
Também a característica do egocentrismo, típico da infância humana, pode ser concebida como uma vantagem funcional. Algumas hipóteses têm sido propostas a esse respeito. Bjorklund e Green (1992) relatam dados da literatura que mostram uma tendência das crianças a superestimarem seu desempenho em várias tarefas. Eles acreditam que essa superestimação pode ter um efeito benéfico na motivação da criança para a realização de tarefas difíceis, resultando em ganhos de longo prazo, na medida em que as crianças não são confrontadas com os previsíveis insucessos.

Assim, Bjorklund e Green (1992) acreditam que o treino precoce da criança em diversos domínios cognitivos seria muito prejudicial ao seu desenvolvimento posterior, porque a estruturação cerebral reduz a flexibilidade geral, uma característica típica e essencial da espécie humana.

A raiz filogenética da neotenia, mais as características do desenvolvimento do cérebro - a exigência de insumos do ambiente extrauterino, inclusive da ação do indivíduo, para o seu completo desenvolvimento, constituem fortes evidências a favor da visão da neotenia humana como uma adaptação constituída por seleção natural. Mas o que acontece quando essa adaptação entra em contato com o mundo real? É obvio que alguns padrões de desenvolvimento, como idade mínima para andar e falar são universais, mas as idades em que as sociedades e os pais esperam que seus filhos alcancem certas realizações variam consideravelmente (Rogoff, 2005).

Com o avanço das neurociências e da psicologia em geral, um conjunto de idéias sobre a importância e a natureza da infância tem emergido, nem sempre autorizadas pelos resultados e interpretações dos estudos, mas, qualquer que seja o caso, com um alto impacto na formação de mentalidades e, por extensão, em políticas públicas voltadas para a infância.

A ideia da importância da infância para a vida adulta, implicando uma conexão causal entre os eventos ocorridos nos primeiros anos e tipos de personalidade da pessoa quando adulta tem sido a pedra de toque da prioridade à infância, do extremo cuidado que se deve ter na criação dos filhos. Uma outra ideia, essa mais recente, é explicitamente baseada em supostos resultados de estudos sobre plasticidade do cérebro, entendida como uma permissão para aprender qualquer coisa e a qualquer época. A conexão entre essas duas ideias tem sido feita de modo a favorecer a seguinte teoria sobre a infância: o cérebro ainda não está desenvolvido ao nascimento e permanece incompleto até a adolescência, talvez mais. Se for proporcionado à criança um volume extra de estimulação, então o adulto resultante será mais inteligente e mais capaz, alcançando um desempenho acima do normal.

Haveria alguma base empírica para sustentar tal teoria? Admitindo que a neotenia da espécie é uma adaptação, resta saber como essa adaptação funciona nas condições presentes. $O$ exame da adaptação em seu funcionamento atual constitui um dos passos do programa adaptacionista (Tooby \& Cosmides, 1995). 
Bjorklund (2006) reviu estudos que examinaram os efeitos do ensino precoce sobre o desempenho posterior. Por exemplo, Harlow (1959), estudando discriminação de objetos em macacos rhesus, submeteu grupos de filhotes de diferentes idades a treinos padronizados em tarefas de discriminação. Quando os mesmos animais foram treinados mais tarde em tarefas mais avançadas de discriminação, os que tinham se submetido ao treino mais precoce mostraram resultados muito abaixo daqueles cujo treino tinha se iniciado mais tarde.

Resultados semelhantes foram obtidos com bebês humanos por Papousek (1977, citado por Bjorklund, 1997). Bebês que começaram o treino de uma tarefa de discriminação ao nascimento demoraram duas vezes mais tempo para atingir o critério, comparados àqueles que começaram o treino aos 31 e aos 44 dias, mesmo controlando a diferença que seria esperada devido à maturação. Resultados na mesma tendência foram encontrados por Little, Lipsitt e Rovee-Collier, em 1984 (citados por Bjorklund, 1997).

Bjorklund assinala a pobreza da pesquisa nessa área - o efeito da aprendizagem segundo o estágio desenvolvimental, impedindo que a análise do problema vá além de simples especulação. No entanto, os poucos dados disponíveis apontam para um problema de alta relevância: a possibilidade de que a estimulação precoce prejudique, em vez de favorecer, 0 desenvolvimento de habilidades no futuro, pelo menos em algumas áreas.

\section{A infância contemporânea}

Se somos uma espécie de vida longa e lenta, com uma infância desproporcionalmente longa, que implicações podemos derivar do modo como tratamos a infância contemporaneamente?

No Brasil, temos assistido nos últimos quarenta anos a mudanças de grande impacto no modo como as crianças são cuidadas. Enquanto a maioria da população vivia em áreas rurais e pequenas cidades até os anos 50, passamos por um intenso e rápido processo de urbanização, com o deslocamento das populações rurais para as cidades, devido à redução de pessoal empregado no setor primário. Como resultado, não só o número de pessoas vivendo em cidades aumentou, como também essas se tornaram megalópoles de vários milhões de habitantes. Outras transformações econômicas e sociais alteraram substancialmente a estrutura da família e os papéis ocupados pelas mulheres. Com sua entrada maciça no mercado de trabalho a partir dos anos 1970, mudanças nas taxas de natalidade e redução do tamanho das famílias, a educação das novas gerações tem sido gradualmente transferida para as instituições de educação infantil, especificamente creches.

Essas mudanças têm sido parte da pauta dos movimentos sociais brasileiros, com importantes repercussões no ambiente acadêmico. A so- 
ciedade reivindica creche de boa qualidade para as crianças, porque essa tem sido uma opção razoável diante das alternativas de deixar a criança em casa, desacompanhada, ou pagar a uma pessoa, geralmente uma muIher com baixa instrução, para cuidar das crianças.

A importância da creche como equipamento social foi levada para o campo acadêmico, alterando-se seu significado para equipamento educacional, como a afirmação de um ideal psicológico e educacional.

Nesse contexto, constatamos uma frequente desvalorização do lugar da brincadeira na educação infantil. Em outro trabalho, Lordelo, Carvalho e Bichara (2008) relataram uma análise da produção científica brasileira sobre a temática da brincadeira na educação: um levantamento na base de dados Index Psi Periódicos Técnico-Científicos (www.bvs-psi.org.br) realizada em 29 de novembro de 2006, recuperou 86 artigos completos que incluíam as palavras-chave brincar ou brincadeira e 101 artigos completos com as palavras educação infantil. Desse conjunto, apenas quatro artigos estavam associados. Esse resultado ilustra o ponto de que os tópicos de educação infantil e da brincadeira têm sido alvos da pesquisa no Brasil, mas sua associação tem sido bem menos frequente.

Não bastasse o fraco interesse pela brincadeira, o modo como o assunto é tratado na educação revela uma visão utilitarista sobre a atividade lúdica, concebida, muitas vezes, como meio através do qual os adultos ensinarão conteúdos, atitudes e habilidades (Lordelo \& Carvalho, 2003). Um exemplo prático servirá para ilustrar o problema.

O Prêmio Qualidade na Educação Infantil (Ministério da Educação, 2004) destacou 24 trabalhos de todas as regiões do Brasil, de professores da educação infantil, que relatavam projetos especiais por eles coordenados. Do total, sete projetos trabalharam especificamente com brincadeiras; todos eles, sem exceção, usaram a brincadeira como meio para alcançar outros objetivos; especificamente, (1) conhecimento e valorização da cultura popular, especificamente a música folclórica da região; (2) aprendizagem de matemática através de brincadeiras; (3) brincadeira e arte como meio de melhorar a autoestima das crianças; (4/5) dois trabalhos sobre interação entre pais e escolas, através do ensino, pelos pais, de brincadeiras do seu tempo; (6) invenção de jogos pelas próprias crianças; (7) conhecimento e valorização de idosos, através de contatos e brincadeiras com avós.

Os outros 17 projetos premiados versaram sobre temas como cidadania, conhecimento da natureza, arte, entre outros temas, e valeram-se, quase sempre, de estratégias ditas lúdicas - jogos e música, sempre para alcançar objetivos ligados às áreas de atuação definidas no Referencial curricular nacional para a educação infantil (Ministério da Educação, 1998). Dos 24 projetos premiados, apenas quatro foram voltados para a faixa etária de zero a três anos. Tomados no conjunto, os trabalhos premiados são uma amostra representativa do pensamento educacional, incluindo professores e autoridades, sobre a natureza da infância e da educação infantil. 
A imaturidade e sua atividade mais característica - a brincadeira - não são tratadas em si mesmas, pelo seu valor intrínseco.

Assim, as concepções correntes no ambiente educacional, bem como no senso comum, mantêm a oposição entre brincadeira e atividade produtiva ou propriamente educacional. Algumas vezes, as rotinas da educação infantil dividem o tempo entre atividade livre (geralmente um tempo menor) e trabalho produtivo, orientado pela professora. As crianças são organizadas em mesinhas, recebem materiais escolares ou indutivos de atividade artística gráfica: papel, tinta, cera, lápis, contas etc. Quando as atividades se destacam dessa rotina cotidiana, como nos projetos relatados do Prêmio Qualidade na Educação Infantil, a mudança se dá pelo uso combinado de várias fontes de informação, pelo contato com pessoas de fora do ambiente escolar, pelo uso de tecnologias não convencionais de educação, como fotografia, filmagem etc. Em qualquer caso, as inovações são sempre pelo uso da brincadeira como veículo, como um meio de aproveitar a motivação natural da criança para brincar, canalizando-a para a "verdadeira" função da educação.

Ou seja, nossa cultura, incluindo pesquisadores em psicologia e educação, bem como pais e professores, todos se apropriam da brincadeira como instrumento de aprendizagem, o que é evidente pela frequência de expressões como brincadeira/brinquedo educativos. Essa visão contribui para distorcer o significado da atividade de brincar, que passa a ser tratada como um fenômeno acidental, e não como deveria ser, como uma adaptação da espécie. Podemos não saber as consequências de ignorar o caráter adaptativo da imaturidade humana (certamente não o sabemos), mas deveríamos estar preocupados com isso, deveríamos ter um programa de pesquisa que avaliasse o impacto de certas experiências na infância sobre o desenvolvimento global e em áreas específicas.

Falar em brincadeira educativa supõe seu oposto. Mas o que seriam exatamente uma e outra? Por exemplo, a brincadeira de luta, em que crianças se engajam em atividade vigorosa, agarrando, empurrando, rolando no chão e, ao mesmo tempo, expressando emoções positivas, inferidas através do sorriso, foi identificada pela primeira vez pelo antropólogo Karl Groos em seu livro"Play of Animals", de 1898 e"Play of Man" de 1901 (Jarvis, 2006). A pesquisa conduzida nos últimos 30 anos do século 20 sugeriu que essa atividade pode ser valiosa para o desenvolvimento de adultos competentes e socialmente maduros. Como é uma forma de brincadeira muito similar às lutas entre crianças, a maioria dos professores sente-se desconfortável em aceitá-la no ambiente escolar. De fato, no Referencial Curricular Nacional para a Educação Infantil não há referência a tal atividade e é bem pouco provável que um professor de educação infantil reconheça nessa brincadeira algum caráter educativo. Em vez disso, o mais provável é que ela seja identificada como briga (inclusive porque as transições entre lutas 
reais e brincadeira de luta costumam ser rápidas). Mas sabemos o suficiente sobre essa brincadeira para ignorá-la?

Decidir o que é educativo ou não, sugerir ou conduzir brincadeiras, será que temos conhecimento suficiente para fazer isso? Na verdade, há alguma evidência de que a interferência externa na atividade da criança, reforçando comportamentos de brincar, reduz o engajamento da criança, como demonstrado por Gomide e Ades (1989). Esses autores conduziram um estudo em que as crianças eram reforçadas com doces enquanto usavam os balanços; mas quando as balas foram temporariamente suspensas, as crianças abandonavam essa atividade. A explicação para esse tipo de resultado está relacionada ao fato de a brincadeira ser considerada como intrinsecamente motivada.

O modelo das motivações intrínsecas (Deci \& Ryan, 1985) implica conceitos como níveis ótimos de ativação e de atenção, que têm sua expressão em ações mais ou menos distanciadas das necessidades de sobrevivência imediata, como complexidade, desafio, incongruência. Assim, a visão de organismo que decorre dessa concepção, aplicada ao ser humano, sustenta a ideia da necessidade humana de desenvolver interações livres no ambiente, reguladas por sentimentos de prazer e de interesse nas próprias ações, bem como necessidade de explorar e manipular o ambiente, pelo prazer intrínseco de eficácia ou competência (Lordelo et al., 2008).

\section{Considerações finais}

Toda a discussão acima arrolada e consubstanciada no que existe em termos de investigação em diversas áreas do conhecimento, relacionadas à psicologia do desenvolvimento, nos levam ao questionamento: o esforço de apropriação da brincadeira com finalidades pedagógicas, associado à crença existente em nossa sociedade de que o sucesso na vida adulta depende de forte investimento desde os anos iniciais em educação, pode ser eficaz? Consideramos que é necessário cogitar a hipótese de que a escolarização precoce e o recrutamento da atividade de brincar intrinsecamente motivada para o ensino de habilidades e conhecimentos específicos podem resultar em prejuízos para a criança e não no seu oposto, como esperado atualmente entre pais e educadores.

Quão seguros estamos sobre o papel das experiências iniciais no desenvolvimento da criança, considerado em seu funcionamento atual e no futuro? Parece-nos importante delinear algumas direções de investigação sobre a questão. Para tal é importante reconhecer a distância entre resultados de pesquisas e sua aplicação à vida real, na formulação de políticas públicas para os grupos interessados. Metas de socialização costumam estar em sintonia com a cultura, entendida no sentido proposto por Keller (1996, 2007), como um conjunto de práticas e crenças compartilhadas, refletin- 
do as demandas dos ambientes, definidos numa perspectiva ecocultural, como ambiente físico, organização societal, práticas e crenças compartiIhadas. Nossas ideias sobre estimulação da criança nos primeiros anos de vida devem refletir, em alguma medida, nossas próprias metas implícitas de socialização, num ambiente em que o ser bem sucedido como adulto implica anos de educação e alguma competição. Como tal, devemos, como pesquisadores, ter o cuidado de examinar nossos pressupostos, expectativas, desejos e dados, distinguindo-os.

Precisamos reconhecer nossa ignorância a respeito da natureza da infância e das consequências de implementar práticas educacionais. A nosso ver, algumas questões se colocam, para o pesquisador em infância, como objeto de reflexão e investigação empírica.

A primeira questão diz respeito à discussão sobre a própria natureza da infância. Qual o significado de "fenômeno biopsicossocial" quando falamos em infância? Quais as implicações da teoria de que a infância é uma construção sócio-histórica (Ariés, 1978)? Num ambiente cujo zeitgeist é majoritariamente ambientalista, convém abrir nosso entendimento para as realizações da etologia, ecologia comportamental e psicologia evolucionista, cujos conhecimentos produzidos têm apontado para a natureza da imaturidade humana como adaptação selecionada naturalmente.

Um segundo tópico de importância diz respeito às consequências da assumida neotenia humana para o desenvolvimento humano em condições ambientais diferenciadas, tomando como referência o ambiente de evolução humana. A chamada estimulação precoce tem algum efeito de curto, médio e longo prazo sobre a criança? Que áreas podem ser afetadas por práticas de estimulação extra? O que é estimulação ótima?

A terceira questão deve focalizar especificamente a brincadeira como sistema motivacional, em suas relações com condições ambientais particulares. $\mathrm{O}$ que acontece quando a criança é impedida de brincar livremente ou quando é conduzida a formas específicas de brincadeira? O que acontece com a própria brincadeira no presente e como certas práticas afetam, posteriormente, o padrão de relacionamento com pares, o envolvimento em jogos e outras atividades?

Finalmente, deveríamos realizar pesquisas sobre modelos pedagógicos específicos, como práticas isoladas e como conjuntos globais de orientações pedagógicas, buscando verificar seus efeitos em áreas diversas, no presente e no futuro. Motivação para brincar, engajamento acadêmico, habilidades sociais, equilíbrio emocional, tudo isso pode estar relacionado ao modo como pensamos e tratamos a infância.

Todas essas questões para reflexão e pesquisa devem, obrigatoriamente, ser consideradas tomando como referência a perspectiva da própria criança. O que ela gosta, o que deseja, o que pensa sobre cada um desses assuntos? Levar a perspectiva da criança a sério, escutar a criança, pode estar aí uma orientação maior. 


\title{
Revisiting the functions of immaturity: a reflection on the concept's relevance for Childhood Education
}

\begin{abstract}
Understanding the nature of childhood may be critical for several areas of research and application. The last decades have witnessed the deconstruction of childhood concepts, based on historical, anthropological and psychological research work, which demonstrate significant social and cultural variability of societies' and historical epochs'conceptions about childhood and child upbringing. Meanwhile, it's increasingly consensual that early education is important and that schools are children's privileged place, detached from the world of adults and particularly from the world of labor. These notions are partially due to pragmatic motives - the need to prepare children for their future insertion in a competitive labor market - and also to theoretic considerations: the assumption of radical socio-cultural and environmental perspectives which construe developing human beings as endowed with unlimited plasticity and liability to immediate and historical environmental contingencies. This paper aims to question these standpoints and to suggest an alternative research agenda on childhood as a bio-psycho-social phenomenon. Human immaturity is focused from an Evolutionary Psychology perspective, as well as recent studies on cognition and metacognition, learning, play and self-esteem, among other themes approached from this perspective. Questions related to childhood education in Brazil, its implicit and explicit curricula and its compatibility with a bio-psycho-social conception of childhood are discussed.
\end{abstract}

Keywords: Childhood. Education. Play. Functions of human immaturity.

\section{Revisitant les fonctions de l'immaturité: une réflexion sur l'importance du concept dans l'école maternelle}

Résumé: La compréhension de la nature de l'enfance peut être critique dans divers domaines d'investigation et d'application. Les dernières décennies ont assisté au travail de déconstruction du concept de l'enfance, en se basant sur les recherches d'historiens, d'anthropologues et de psychologues, qui ont démontré l'intense variabilité sociale et culturelle sur la façon dont les sociétés et les époques pensent de l'enfance et choisissent de l'aborder.En même temps, le consensus social sur l'importance de l'éducation dès les premières années de vie, ainsi que sur l'école en tant qu'espace privilégié pour l'enfant, distant du monde des adultes et particulièrement du monde du travail, se consolide. Ces idées sont orientées d'une part pour des raisons pragmatiques - le besoin de préparation de l'enfant pour sa future insertion dans le monde du travail, dans des conditions compétitives, et d'autre part pour des motifs théoriques - l'adoption d'une perspective socioculturelle et contextualiste radicale, qui 
voit l'être humain en développement comme du matériel souple, à peine astreint aux pressions environnementales et historiques. Cet article cherche à clarifier les limitations de telles positions et proposer, à leur place, un plan de recherche sur l'enfance en tant que phénomène biopsychosocial. Pour cela, il examine les idées de la psychologie évolutionniste sur l'immaturité humaine et les études les plus récentes orientées par cette perspective, en s'étendant sur des items comme la cognition et la métacognition, l'apprentissage, l'estime de soi et le jeu, entre autres. Finalement, l'article discute les problèmes de l'organisation de l'école maternelle au Brésil, ses cursus explicite et implicite, et la compatibilité de cette étape de l'éducation avec une conception biopsychosociale de l'enfance.

Mots-clés: Enfance. Éducation. Jeu. Fonctions de l'immaturité.

\section{Reexaminando las funciones de la inmadurez: una reflexión sobre la relevancia del concepto en la Educación Infantil}

Resumen: La comprensión sobre la naturaleza de la infancia puede ser crítica para las varias áreas de investigación y aplicación. Las últimas décadas asistieron al trabajo de des-construcción del concepto de infancia, teniendo como basis las investigaciones de historiadores, antropólogos y psicólogos, que evidenciarón la intensa variabilidad social y cultural en el modo como las sociedades y las épocas piensan sobre la infancia y deciden como tratarla. Al mismo tiempo, gana fuerza el consenso social sobre la importancia de la educación desde los primeros años de vida,y sobre la escuela como lugar privilegiado para el niño, alejado del mundo de los adultos, particularmente del mundo del trabajo. Esas ideas son orientadas de un lado por motivos pragmáticos - la necesidad de preparación del niño para su futura inserción en el mundo del trabajo, en condiciones competitivas, y por otro por motivos teóricos - la adopción de una perspectiva sociocultural e contextual extremada, que ve al ser humano en desarrollo como material plástico, sujeto a no más que a los condicionantes ambientales inmediatos y históricos. Este artículo busca esclarecer a las limitaciones de tales posiciones y proponer, en lugar de ellas, una agenda de pesquisa sobre la infancia como fenómeno bio-psico-social. Para tal, examina las ideas de la psicología evolucionista sobre la inmadurez de la especie humana, y los estudios más recientes orientados por esa perspectiva, cubriendo tópicos como cognición y meta-cognición, aprendizaje, auto-estima y juego, entre otros. Finalmente, el artículo discute los problemas de la organización de la educación infantil en Brasil, sus currículos explícito

y implícito, y la congruencia de esa organización con una concepción bio-psico-social de infancia.

Palabras-clave: Infancia. Educación. Juego. Funciones de la inmadurez. 


\section{Referências}

Ariès, P. (1978). História social da criança e da família. Rio de Janeiro: Zahar.

Bjorklund, D. F. (1997). The role of immaturity in human development. Psychological Bulletin, 122, 153-169.

Bjorklund, D. F. (2006). The evolution and function of adult attachment: A comparative and phylogenetic analysis. Journal of Personality and Social Psychology, 89, 731-746.

Bjorklund, D. F., \& Green, B. L. (1992). The adaptive nature of cognitive immaturity. American Psychologyst, 47, 46-54.

Bruner, J. S. (1976). Nature and uses of immaturity. In J. S. Bruner, A. Jolly \& K. Sylva (Orgs.), Play - Its role in development and evolution (pp. 28-65). London: Penguin.

Byers, J. A. (1998). The biology of human play. Child Development 69, 599-600.

Deci, E. L., \& Ryan, R. M. (1985). Intrinsic motivation and self-determination in human behavior. New York: Plenum.

Gomide, P. I. C., \& Ades, C. (1989). Effects of reward and familiarity of reward agent on spontaneous play in preschoolers: A field study. Psychological Reports, 65, 427-434.

Gould, S. J. (1977). Ontogeny and phylogeny. Cambridge: Harvard University Press.

Harlow, H. F. (1959, dezembro). The development of learning in the Rhesus monkey. American Scientist, 47, 459-479.

Jarvis, P. (2006). "Rough and Tumble" play: Lessons in life. Evolutionary Psychology, 4, 330-346.

Johnson, M. H. (1999). Developmental neuroscience. In M. H. Bornstein \& M. E. Lamb (Orgs.), Developmental psychology: An advanced textbook (pp. 199-230). Mahwah: Lawrence Erlbaum.

Keller, H. (1996). Evolutionary approaches. In J. W. Berry, Y. H. Poortinga \& J. Pandey (Orgs.), Handbook of cross-cultural psychology (Vol 1, pp. 215-256). Boston: Allyn and Bacon.

Keller, H. (2007). Cultures of infancy. Mahwah: Lawrence Erlbaum.

Kurzban, R., \& Haselton, M. G. (2006). Making hay out of straw? Real and imagined controversies in evolutionary psychology. In J. H. Barkow (Org.), Missing the revolution: Darwinism for social scientists (pp. 149-162). New York: Oxford University Press.

Leakey, R. E., \& Lewin, R. (1992). Origins reconsidered. New York: Anchor Books.

Lordelo, E. R., \& Carvalho, A. M. A. (2003). Educação infantil e psicologia: para quê brincar? Psicologia Ciência e Profissão, 23(2), 14-21.

Lordelo, E. R., Carvalho, A. M. A., \& Bichara, I. D. (2008). Infância roubada: brincadeira e educação infantil no Brasil. In L. V. C. Moreira \& A. M. Carvalho (Orgs.), Família e educação: olhares da psicologia. São Paulo: Paulinas.

Lutz, D. J., \& Sternbeg, R. J. (1999). Cognitive development. In M. H. Bornstein \& M. E. Lamb (Orgs.), Developmental psychology: An advanced textbook (pp. 275-311). Mahwah: Lawrence Erlbaum. 
Maynard-Smith, J. (1966). Teoría de la evolución. Madri: Ediciones Istmo.

Ministério da Educação. Secretaria de Educação Fundamental. (1998). Referencial Curricular Nacional para a Educação Infantil. Brasília, DF: Autor.

Ministério da Educação. Secretaria de Educação Fundamental. (2004). Prêmio Qualidade na Educação Infantil. Brasília, DF: Autor.

Moore, D. S. (2008). Individuals and populations: How biology's theory and data have interfered with the integration of development and evolution. New Ideas in Psychology, 26, 370-386.

Pellegrini, A. D., \& Smith, P. K. (1998). The development of play during childhood: Forms and possible functions. Child Psychology and Psychiatry Review, 3(2), 51-57.

Pellegrini, A. D., Hovart, M., \& Huberti, P. (1998). The relative costs of physical play. Animal Behavior, 55, 1053-1061.

Pianka, E. R. (1970). On $r$ and K selection. American Naturalist, 104, 592-597.

Portmann, A. (1945). Die Ontogênese des Menschen als Problem der Evolutionsforschung. Verhandlung der schweizerischen naturforschenden Gesellschaft, 44-53.

Rogoff, B. (2005). A natureza cultural do desenvolvimento humano (R. Cataldo Costa, trad.). Porto Alegre: Artes Médicas.

Seligman, M. (1977). Desamparo aprendido: sobre depressão, desenvolvimento e morte. São Paulo: Hucitec.

Spinka, M., Newberry, R. C., \& Bekoff, M. (2001). Mammalian play: Training for the unexpected. Quarterly Review of Biology, 76, 141-168.

Tooby, J., \& Cosmides, L. (1995). The psychological foundations of culture. In J. H. Barkow, L. Cosmides \& J. Tooby (Orgs.), The adapted mind: Evolutionary psychology and the generation of culture (pp. 19-136). New York: Oxford University Press.

Eulina da Rocha Lordelo, Professor Associado da Universidade Federal da Bahia. Endereço para correspondência: Rua Ranulfo Oliveira, 1007, ap. 202, CEP 40155-030.Salvador, BA, Brasil. Endereço eletrônico: eulina@ufba.br

Ilka Dias Bichara, Professor Associado da Universidade Federal da Bahia. Endereço para correspondência: Ladeira do Acupe, 856, ap. 704, CEP 40290-160. Salvador, BA, Brasil. Endereço eletrônico: ilkadb@ufba.br

Recebido em: 19/02/2009

Aceito em: 18/05/2009 